\title{
The Tobacco Control Scale: a new scale to measure country activity
}

\section{Joossens, M Raw}

See end of article for authors' affiliations ......................

Correspondence to: Luk Joossens, Belgian Foundation Against Cancer; Association of the European Cancer Leagues, 479 Chaussee de Louvain, Brussels B-1030, Belgium; joossens@globalink.org

Received 4December 2005 Accepted 27 March 2006
Objectives: To quantify the implementation of tobacco control policies at country level using a new Tobacco Control Scale and to report initial results using the scale.

Method: A questionnaire sent to correspondents in 30 European countries, using a scoring system designed with the help of a panel of international tobacco control experts.

Results: The 30 countries are ranked by their total score on the scale out of a maximum possible score of 100. Only four countries (Ireland, United Kingdom, Norway, Iceland) scored 70 or more, with an eight point gap (most differences in scores are small) to the fifth country, Malta, on 62. Only 13 countries scored above 50, 11 of them from the European Union (EU), and the second largest points gap occurs between Denmark on 45 and Portugal on 39, splitting the table into three groups: 70 and above, 45 to 62,39 and below. Ireland had the highest overall score, 74 out of 100, and Luxembourg was bottom with 26 points. However even Ireland, much praised for their ban on smoking in public places, did not increase tobacco taxes in 2005, for the first time since 1995.

Conclusions: Although the Tobacco Control Scale has limitations, this is the first time such a scale has been developed and applied to so many countries. We hope it will be useful in encouraging countries to strengthen currently weak areas of their tobacco control policy.
$\mathrm{T}$ here is evidence that comprehensive tobacco control programmes reduce smoking prevalence. ${ }^{1}$ However, there have been relatively few attempts so far to measure the implementation of tobacco control policies systematically at country level. This paper has two main aims: to quantify the implementation of tobacco control policies at country level using the new Tobacco Control Scale (TCS); to report initial results using the scale. The scale is based on six policies which, according to the evidence, should be prioritised in comprehensive tobacco control programmes. They are described by the World Bank ${ }^{1}$ and listed below. We describe how a questionnaire was designed to quantify the implementation of these interventions at country level, and how a scoring system was designed to create the scale. Finally we present initial results, showing countries ranked by their TCS score, and discuss the merits and limitations of the scale.

\section{The World Bank list of effective tobacco control interventions}

The June 2003 World Bank fact sheet, Tobacco control at a glance ${ }^{1}$ described six cost effective tobacco control interventions:

- price increases through higher taxes on cigarettes and other tobacco products

- bans/restrictions on smoking in public and work places

- better consumer information, including public information campaigns, media coverage, and publicising research findings

- comprehensive bans on the advertising and promotion of all tobacco products, logos and brand names

- large, direct health warning labels on cigarette boxes and other tobacco products

- treatment to help dependent smokers stop, including increased access to medications.

The evidence suggests that the best results are achieved when a comprehensive set of measures are implemented together. ${ }^{23}$ We briefly review these six interventions here.

\section{Price increases through higher taxes on tobacco products}

According to the World Bank, price increases are the most effective and cost effective tobacco control measure, especially for young people and others on low incomes, who are highly price responsive. A price rise of $10 \%$ decreases consumption by about $4 \%$ in high-income countries. ${ }^{4}$ The impact of price can be illustrated by what happened in France and the Netherlands.

During 2003 the price of the leading brand in France, Marlboro-with about 30\% market share-increased by $31 \%$ while cigarette sales fell $13.5 \%$. European cigarette tax policy is based on the price of the most popular price category in each country. In France, Marlboro is the most popular price category and thus is a good indicator of tax and price policy for cigarettes in France. Surveys conducted in November/ December 1999 and 2003 showed that the proportion of smokers in France decreased from 35\% to 30\%, a fall of almost two million smokers. Furthermore in 2003 more smokers said they wanted to stop (66\% v 58\% in 1999) and price became the main reason they wanted to stop smoking (fourth place in 1999). ${ }^{5}$ In the Netherlands in February 2004, the price of a pack of Marlboro increased by just over $18 \%$. During the year 2004 cigarette sales decreased by $12.8 \%$ and the number of smokers fell from 3950000 in 2003 to 3690000 in 2004, almost 7\% fewer. ${ }^{6}$

\section{Bans/restrictions on smoking in public and work places}

The most extensive clean indoor air laws prohibit smoking in work places, on public transport, and in other public places, including restaurants and bars. Smoke-free workplaces not only protect non-smokers, they also create an environment

Abbreviations: CDC, US Centers for Disease Control and Prevention ENSP, European Network for Smoking Prevention; FCTC, Framework Convention on Tobacco Control; GDP, gross domestic product; PPS, purchasing power standards; TCS, Tobacco Control Scale 
that encourages smokers to cut down or stop. A review of 26 studies of the effect of smoke-free workplaces concluded that totally smoke-free workplaces are associated with reduction in prevalence of about $4 \% .^{7}$ People in work places that changed to-or maintained-smoke-free policies between 1993 and 2001 were almost twice as likely to stop smoking than people whose work places did not do so. ${ }^{8}$

In Europe, bans on smoking in the workplace (including bars and restaurants) have been introduced in Ireland (March 2004), Norway (June 2004), Italy (January 2005), Malta (April 2005), Sweden (June 2005), and Scotland (March 2006). Figures released by the Office of the Revenue Commissioners show a 15\% fall in cigarette sales during 2004 in Ireland. They said: "this shortfall reflected changes in smoking patterns, which were affected by, amongst other things, the introduction of the smoke free workplace legislation". ${ }^{9}$ The Irish cigarette smoking prevalence data bear this out, falling from $25.5 \%$ in March 2004 to $23.6 \%$ in August $2005 .{ }^{10}$ Italy also saw a decline: 28.3 million kg of cigarettes were sold in January-April 2005, compared with 31.1 million $\mathrm{kg}$ in the same period in 2004, a $9 \%$ reduction. ${ }^{11}$

\section{Better consumer information, spending on public information campaigns}

Our questionnaire measures national government spending on tobacco control, including spending on mass communication campaigns, treatment, and other tobacco control activities. Experience from the USA and Australia ${ }^{12}$ shows that increases in funding for tobacco control programmes reduce tobacco use. In the USA several states have invested in large-scale comprehensive, tobacco control programmes, including components such as media campaigns, school based programmes, treatment including telephone quit lines, and enforcement of smoking restrictions. The US data show a consistent pattern relating tobacco control expenditure to cigarette sales, ${ }^{13}$ with the effectiveness of mass media campaigns depending on their scale and duration. Expenditures have to be high enough to reach smokers sufficiently often and for long enough. The US Centers for Disease Control and Prevention (CDC) estimated that states need to spend between $\$ 1$ and $\$ 3$ per capita per year over at least three years to be effective. ${ }^{14}$

\section{Comprehensive bans on the advertising and promotion of all tobacco products}

Empirical evidence shows that a fully comprehensive advertising ban covering all media and all forms of direct and indirect advertising reduces tobacco consumption. A study of 22 high-income countries based on data from 1970 to 1992 concluded that comprehensive bans on cigarette advertising and promotion can reduce smoking, but that partial bans have little or no effect. If the most comprehensive restrictions were in place, the study concluded, tobacco consumption would fall by more than $6 \%$ in high income countries. ${ }^{15}$

\section{Large, direct health warnings on tobacco product packaging}

Evidence from Canada, Brazil, Netherlands and Australia shows that their recently introduced, large warnings discourage smoking and increase awareness of the harmful effects of smoking. Tobacco product warning labels are effective in informing smokers of the hazards of smoking, encouraging them to stop, and discouraging non-smokers from starting. ${ }^{16} 17$

\section{Treatment to help dependent smokers stop}

Most smokers want to stop but many need help to do so because of their dependence. In the UK, for example, about

\section{Table 1 The expert panel}

Fiona Godfrey, Consultant, European Respiratory Society, Luxembourg Albert Hirsch, Professor of Pneumology, University of Paris, and Vice President, French League Against Cancer, France

Luk Joossens, Tobacco Control Manager, Belgian Foundation Against Cancer, and Advocacy Officer, Association of the European Cancer Leagues, Belgium

Ann McNeill Honorary Senior Research Fellow, University College London, University of London, UK

Paul Nordgren, National Health Administrator, National Institute of Public Health, Sweden

Juan Ramon Villalbi, Past President, Spanish National Committee on Smoking Prevention (CNPT), Spain

Tibor Szilagyi, CEO, Health 21 Foundation, Hungary

Kenneth Warner, Dean of the School of Public Health, University of

Michigan, and Director University of Michigan Tobacco Research

Network, USA

Marc Willemsen, Research Manager, Head of Research, Stivoro,

Netherlands

Witold Zatonski, Professor of Epidemiology, University of Warsaw, and Director of the Division of Cancer Epidemiology and Prevention at the Maria Sklodowska-Curie Memorial Cancer and Institute of Oncology, Poland

$70 \%$ of smokers each year say they would like to stop but only a third make an attempt, and only $2-3 \%$ succeed in stopping for at least one year. ${ }^{18}$ One major reason for such a low cessation rate is the addictiveness of nicotine. Many smokers need help to stop. However, effective treatments exist, in the form of behavioural support (including telephone help lines) and medications, ${ }^{19}{ }^{20}$ and need to be made more widely available to smokers. Although their impact on prevalence is low they are important because they help heavier, more dependent smokers, who have the most difficulty stopping and who place a heavier burden on health care services. In England such treatment services are now nationally available to all smokers through the National Health Service, free at the point of use (that is, paid out of general taxation)..$^{21}$

\section{METHODS}

In 2004 the European Network for Smoking Prevention (ENSP), with financial support from the European Commission, provided a grant to one of the authors (LJ) to measure tobacco control activity at country level in Europe. ${ }^{22}$ A questionnaire was drafted then finalised with feedback from a panel of experts (table 1). In 2004 the questionnaire was sent to the ENSP correspondents in 28 countries who had agreed to fill in their country data. They were nominated by ENSP because they were the official country representatives to ENSP, members of their national coalition and thus knowledgeable about tobacco control (table 2). The questionnaire was sent to the 25 countries of the European Union (EU) plus Iceland, Norway and Switzerland (table 3).

Although the original intention of the project was simply to describe current tobacco control policies in Europe, it seemed worthwhile trying to quantify these policies, in order to compare countries more systematically. However, while we have evidence telling us broadly which tobacco control measures are effective, it is not easy to decide what weight should be given to each policy in a scale. This might be decided by the size of the effect of a policy measure, but relatively little rigorous research on the effectiveness of tobacco control policy exists, and such research that does exist is not precise enough to permit easy comparisons between countries. Therefore, in order to score the questionnaire and create the scale we had to assign scores to each tobacco control policy. To do this ENSP convened a panel of experts to agree the allocation of points to the scale. The panel exchanged emails from January to April 2004 and some of them met during an ENSP meeting in Krakow in May 
Table 2 National correspondents who filled in the Tobacco Control Scale questionnaire

\begin{tabular}{|c|c|c|}
\hline Country & Name & Organisation \\
\hline Austria & Manfred Neuberger & University of Vienna \\
\hline Belgium & Luk Joossens & Belgian Foundation against Cancer \\
\hline Bulgaria & George Kotarov & National Centre of Public Health \\
\hline Cyprus & Stelios Sycallides & $\begin{array}{l}\text { Cyprus National Coalition for the Prevention of } \\
\text { Smoking }\end{array}$ \\
\hline Czech Rep & Katerina Langrova, Eva Kralikova & $\begin{array}{l}\text { Czech Coalition against Tobacco, Charles } \\
\text { University of Prague }\end{array}$ \\
\hline Denmark & Jorgen Falk & National Board of Health. \\
\hline Estonia & Andrus Lipand & Ministry of Social Affairs of Estonia \\
\hline Finland & Mervi Hara & Suomen ASH \\
\hline France & Bertrand Dautzenberg & Office Français du prévention du tabagisme (OFT) \\
\hline Germany & Martina Poetschke Langer & German Cancer Research Centre \\
\hline Greece & $\begin{array}{l}\text { Maria Pilali, Evangelos } \\
\text { Polychronopoulos, Nicolas Kordiolos }\end{array}$ & $\begin{array}{l}\text { Hellenic Cancer Society, Hellenic Cancer Society, St } \\
\text { Savvas Cancer Hospital }\end{array}$ \\
\hline Hungary & Tibor Szilagyi & Health 21 Hungarian Foundation \\
\hline Iceland & Jacobina Arnadottir & Tobacco Control Task Force of Iceland \\
\hline Ireland & Valerie Coglan & ASH Ireland \\
\hline Italy & Elizabeth Tamang & $\begin{array}{l}\text { Centro Regionale di Referimento per la Prevenzione } \\
\text { (CRP), Regione del Veneto }\end{array}$ \\
\hline Latvia & Janis Caunitis & Health Promotion Centre \\
\hline Lithuania & Aurelijus Veryga & Kaunas University of Medicine \\
\hline Luxembourg & Marina Tomasic & Fondation Luxembourgeoise contre le Cancer \\
\hline Malta & Elaine Caruana & Health Promotion Department \\
\hline Netherlands & Marc Willemsen & Foundation on Smoking or Health (Stivoro) \\
\hline Norway & Siri Naesheim, Rita Lindbak, Hege Wang & Directorate for Health and Social Affairs \\
\hline Poland & Witold Zatonski & Cancer Centre and Institute of Oncology \\
\hline Portugal & Luis Reis Lopez & Portuguese Smoking Prevention Council \\
\hline Romania & Luminita Sanda & Ministry of Health \\
\hline Slovakia & Darina Sedlakova & WHO Country Office in Slovakia \\
\hline Slovenia & Ann Luin & Slovenian coalition for tobacco control \\
\hline Spain & Teresa Salvador Llivina & National Committee for Smoking Prevention (CNPT) \\
\hline Sweden & Margaretha Haglund & National Institute of Public Health \\
\hline Switzerland & Verena El Fehri & Association Suisse pour la Prévention du Tabagisme \\
\hline UK & Ben Youdan & No Smoking Day \\
\hline
\end{tabular}

2004. The panel included a leading American tobacco control economist, who was the World Bank representative to the World Health Organization Framework Convention on Tobacco Control (FCTC) negotiations in Geneva, and tobacco control experts from different regions in Europe. On average the participants had more than 20 years experience in tobacco control. They contributed mostly to the weighting of price, smoke-free policies and advertising, mainly by email. None refused to join the project.

In summer 2005 the questionnaire survey was repeated with 30 European countries: the previous 28 plus two accession countries, Bulgaria and Romania. Data were collected using the 2004 questionnaire, but stricter definitions were applied in the scale to smoke-free places and smoking treatment systems.

\section{The scale}

The questionnaire and raw data are available on the Tobacco Control website-http://www.tobaccocontrol.com/supplemental. The Tobacco Control Scale (TCS), showing the points allocated to each policy, with a maximum potential score of 100 , is shown in table 3. The right column/blue rows show the maximum points that can be scored for each policy. The questionnaire asked about legislation in force on the 1 July 2005, price data on 1 January 2005, and the 2004 tobacco control budget. Thus any legislation, price increases or funding introduced after those dates, as has happened or will happen for example in Spain, Scotland, Estonia, Belgium and England, are not included.

The following data sources (apart from the questionnaire) were used to score the scale:

- the price of a pack of Marlboro (20 pieces) on 1 January 2005 was based on a Citigroup Smith Barney report ${ }^{23}$
- the price of a pack of 20 cigarettes in the most popular price category on 1 January 2005 was based on the 2005 European Commission report "Excise duty tables"24

- Gross domestic product (GDP) expressed in purchasing power standards (PPS) per capita and GDP in 2004, and country population data on 1 January 2004 were collected from the statistical office of the European Union $^{25}$

- information on legislation obtained from the correspondents via the questionnaire was discussed and verified at the WHO tobacco legislation database during a visit to the European regional office in July 2005; provisional scores were sent in July 2005 to the 30 country correspondents for comment.

The most common problem in assigning points remained the subjectivity involved in assessing enforcement/implementation. For example, there is room for interpretation of the extent to which a law is enforced or what for a treatment system constitutes "selected areas" or "the whole country". We relied on the judgement of our correspondents, familiar with the situation in their country. Although we think the most accurate and reliable data are likely to come from experienced tobacco control professionals in their own country, we acknowledge that this scale depends critically on their judgement, and that in principle it would be worthwhile developing more sophisticated measures of implementation (see Discussion).

\section{RESULTS}

The results are shown in table 4 . Countries are ranked by score, with the maximum possible score for each policy shown in brackets at the top. Only four countries score 70 or more (Ireland, UK, Norway, Iceland) with an eight point gap (differences in scores are mostly very small) to the fifth 
Table 3 The Tobacco Control Scale

Price of cigareftes and other tobacco products

Price of Marlboro, and price of most popular price category, in January 2005 - additive

The price of Marlboro in January 2005, taking into account Gross Domestic Product per capita expressed in Purchasing Power Standards (PPS). 15

Country with highest price ratio receives 15 points. (see notes)

The price of a packet of cigarettes in the most popular price category in January 2005, taking into account Gross Domestic Product per capita 15 expressed in the PPS. Country with highest price ratio receives 15 points.

Smoke free work and other public places on 1 July 2005

Workplaces excluding cafes and restaurants - one only of

Complete ban without exceptions (no smoking rooms); enforced

Complete ban, but with closed, ventilated, designated smoking rooms; enforced

Complete ban, but with ventilated, designated smoking rooms; enforced

Meaningful restrictions; enforced

Legislation, but not enforced

Cafes and restaurants - one only of

Complete ban; enforced

Complete ban, but with closed, ventilated, designated smoking rooms; enforced

Meaningful restrictions; enforced

Legislation, but not enforced

Public transport and other public places - additive

Complete ban in domestic trains without exceptions

Complete ban in other public transport without exceptions

Complete ban in educational, health, government and cultural places without exceptions

OR Ban in educational, health, government and cultural places, but with designated smoking areas or rooms

Spending on public information campaigns in 2004

Tobacco control spending by the government in 2004 , as a proportion of Gross Domestic Product (GDP). Country with highest ratio receives

15 points (see notes).

Comprehensive bans on advertising and promotion on 1 July 2005

Points for each type of ban included - additive

Complete ban on tobacco advertising on television

Complete ban on outdoor advertising (e.g. posters)

Complete ban on advertising in print media (e.g. newspapers and magazines)

Ban on point of sale advertising

Ban on cinema advertising

Ban on sponsorship

Ban on internet advertising

Ban on radio advertising

Large direct health warning labels on 1 July 2005

Rotating health warnings

Size of warning - one only of

$10 \%$ or less of packet

$11-25 \%$ of packet

$26-40 \%$ of packet

$41 \%$ or more of packet

Contrasting colour (e.g. black lettering on white background)

A picture

Treatment to help dependent smokers stop

Quitline - one only of

Well funded national quitline or well funded quitlines in all major regions of country

OR National quitline with limited funding or a patch work of small local quitlines

Network of smoking cessation support

Reimbursement of treatment

Cessation support network covering whole country (3); free (3)

Cessation support network, but only in selected areas, e.g. major cities (2); free (3)

Cessation support network covering whole country (3), partially free (2)

Cessation support network, but very limited, just a few centres (1), free (3)

Cessation support network, but only in selected areas, e.g. major cities (2), partially free (2)

Cessation support network covering whole country (3), not free (0)

Cessation support network, but very limited, just a few centres (1), partially free (2)

Cessation support network, but only in selected areas, e.g. major cities (2); not free (0)

Cessation support network, just a few centres (1), not free (0)

Reimbursement of medications - one only of

Reimbursement of pharmaceutical treatment products

OR Partial reimbursement of pharmaceutical treatment products

Maximum possible score

Table notes. Cigarette price: Gross Domestic Product can be expressed in PPS (purchasing Power Standard). PPS per capita has been used to take account of real purchasing power in different countries; points are awarded using the same method as for public information campaign spending. Public information campaign spending: the top country, the UK, is awarded 15 points; the UK ratio (spending/GDP) is then divided by 15 and the resulting number gets 1 point; countries achieve points for multiples of that number. For a more detailed explanation please see tobcon url. Advertising: television is the medium most used for tobacco advertising in countries with no advertising restrictions; outdoor advertising (e.g. posters) is a prominently used medium when television advertising is banned; indirect advertising (e.g. clothing, watches, or other products with cigarette branding, is the industry's favoured loophole when there are otherwise comprehensive advertising bans. Why rankings for price and spending? PPS takes account of affordability within a country. This introduces a (constantly changing) ratio, rather than absolute figures. In order to simplify this abstract ratio ranking system, we attributed the highest score to the country with the highest ratio. The method is best understood by consulting the raw data and resulting points scored, on the website. 
Table 4 European countries ranked by total Tobacco Control Scale score

\begin{tabular}{|c|c|c|c|c|c|c|c|}
\hline Country & $\begin{array}{l}\text { Price } \\
(30)\end{array}$ & $\begin{array}{l}\text { Public place } \\
\text { bans (22) }\end{array}$ & $\begin{array}{l}\text { Public info campaign } \\
\text { spending (15) }\end{array}$ & $\begin{array}{l}\text { Advertising } \\
\text { bans (13) }\end{array}$ & $\begin{array}{l}\text { Health warnings } \\
\text { (10) }\end{array}$ & $\begin{array}{l}\text { Treatment } \\
\text { (10) }\end{array}$ & $\begin{array}{l}\text { Total } \\
(100)\end{array}$ \\
\hline Ireland & 23 & 21 & 3 & 12 & 6 & 9 & 74 \\
\hline UK & 30 & 1 & 15 & 11 & 6 & 10 & 73 \\
\hline Norway & 26 & 17 & 5 & 13 & 6 & 4 & 71 \\
\hline Iceland & 25 & 11 & 13 & 13 & 6 & 2 & 70 \\
\hline Malta & 19 & 17 & 3 & 9 & 7 & 7 & 62 \\
\hline Sweden & 19 & 15 & 2 & 13 & 6 & 5 & 60 \\
\hline Finland & 18 & 12 & 1 & 13 & 7 & 7 & 58 \\
\hline Italy & 16 & 17 & 2 & 10 & 6 & 6 & 57 \\
\hline France & 23 & 6 & 4 & 11 & 6 & 6 & 56 \\
\hline Netherlands & 16 & 9 & 4 & 12 & 6 & 5 & 52 \\
\hline Cyprus & 21 & 6 & 1 & 12 & 6 & 5 & 51 \\
\hline Poland & 16 & 10 & 0 & 12 & 6 & 6 & 50 \\
\hline Belgium & 16 & 8 & 2 & 12 & 7 & 5 & 50 \\
\hline Slovakia & 18 & 8 & 0 & 11 & 6 & 6 & 49 \\
\hline Hungary & 17 & 6 & 1 & 10 & 6 & 7 & 47 \\
\hline Bulgaria * & 19 & 6 & 0 & 9 & 6 & 6 & 46 \\
\hline Estonia & 14 & 9 & 2 & 11 & 1 & 8 & 45 \\
\hline Denmark & 17 & 3 & 2 & 10 & 6 & 7 & 45 \\
\hline Portugal & 17 & 5 & - & 10 & 6 & 1 & 39 \\
\hline Greece & 17 & 7 & 0 & 4 & 6 & 4 & 38 \\
\hline Czech Republic & 12 & 6 & 0 & 9 & 6 & 5 & 38 \\
\hline Germany & 20 & 2 & 0 & 4 & 6 & 4 & 36 \\
\hline Slovenia & 13 & 6 & 0 & 7 & 6 & 4 & 36 \\
\hline Switzerland & 15 & 5 & 4 & 4 & 3 & 4 & 35 \\
\hline Lithuania & 11 & 6 & 1 & 9 & 6 & 1 & 34 \\
\hline Spain & 12 & 3 & 3 & 3 & 6 & 4 & 31 \\
\hline Austria & 14 & 4 & 0 & 4 & 6 & 3 & 31 \\
\hline Latvia & 9 & 6 & 1 & 6 & 6 & 1 & 29 \\
\hline Romania* & 13 & 6 & 0 & 0 & 3 & 5 & 27 \\
\hline Luxembourg & 7 & 4 & 0 & 5 & 7 & 3 & 26 \\
\hline
\end{tabular}

Bold countries are EU members; *accepted to join EU; other, non-EU; - no data. The 10 countries which joined the EU in 2004 are: Cyprus, Czech Republic, Estonia, Hungary, Latvia, Lithuania, Malta, Poland, Slovakia, Slovenia.

country, Malta, on 62. Only 13 countries score above 50, 11 of them from the EU, and the second largest gap occurs between Denmark on 45 and Portugal on 39, splitting the table into three groups: 70 and above, 45 to 62, 39 and below.

\section{DISCUSSION}

\section{Will this scale be useful?}

The purpose of this new scale is to introduce a new level of systematisation into scoring tobacco control at country level. This has never been done in so many countries and we hope the scale will be used even more widely, encouraging comparisons between countries and thus motivation to strengthen weak polices. We hope countries will not use it to boast of their success or rest on their laurels. All countries had low scores in some policy areas.

Norway and Iceland, for example, have low scores for treatment, while the UK and Lithuania have the lowest score on public place smoking bans, although the new English law, due to be implemented in 2007, will change this. Ireland increased its total score substantially as a result of its smokefree legislation, for which, along with New York City, it gained considerable publicity. Ireland has been an inspiring example to many, and yet has a low score for campaign spending, and did not increase tobacco taxes in 2005, the first time since 1995.

\section{Current limitations of the scale}

Levy, Chaloupka and Gitchell described the effects of tobacco control policies on smoking rates and developed a tobacco control scorecard. They argued that large price increases through taxation and comprehensive clean air laws appear were most successful in reducing smoking rates, with each having the potential to reduce smoking prevalence by $10 \%$ or more. They also argue that media campaigns are effective when implemented with other polices, and they present evidence that all six of the policies in the World Bank paper are effective. ${ }^{3}$ Our expert panel agreed that prices and smokefree places should receive the most points. However, they found it more difficult to decide the points allocation for advertising bans and for bans in specific media, and we have already acknowledged the difficulty of objectively measuring enforcement of some policies.

We were also unable to quantify some components of tobacco control policy which we believe are extremely important for public health and which, ideally, should be included in the scale:

- spending on research to inform and underpin tobacco control policy

- media coverage of tobacco control issues, which to a large extent reflects the skill and energy of tobacco control advocates and organisations

- anti-smuggling measures.

Tobacco control research in Europe is extremely fragmented $^{26}$ and severely underfunded, and we were unable to obtain reliable data on research and research spending at country level. The lack of rigour of much research on the effectiveness of tobacco control policies is surprising in view of smoking's huge impact on health and healthcare spending, and the enormous public health impact of reducing tobacco use. ${ }^{27}$ Information on media coverage has proved too difficult to collect in 30 countries with more than 20 languages and would itself require a sizeable research project. Finally, with the exception of the $\mathrm{UK}_{,}{ }^{28}$ most countries do not have formal anti-smuggling strategies. Even if they did they would be difficult to evaluate as they are generally confidential. Success in the fight against smuggling is possible but usually happens as a result of coordinated, international actions. ${ }^{29}$

Scoring systems have been developed by others. Gilpin and colleagues developed an index for US state tobacco control outcomes based on cigarette prices and workplace and home 


\section{What this paper adds}

There are published studies describing scoring systems for tobacco control programmes but none has developed a systematic scoring system that can be used in many different countries with different languages, legal systems, etc. The Tobacco Control Scale uses a systematic scoring system that permits comparison in 30 European countries, and this study presents preliminary results using the new scale.

smoking bans. ${ }^{30}$ Chriqui and colleagues ${ }^{31}$ applied a rating system to state indoor air laws in the USA, and the American Lung Association measures tobacco control activities at state level based on spending, smoke-free air laws, cigarette excise tax and youth access laws. ${ }^{32}$ However, these systems compare tobacco control policies within the same legal system, so measurement of enforcement, and comparisons, are easier. As far as we know the TCS is the first scale to be developed for use in so many countries. We hope it will be used and tested in many more.

As we have indicated, we think it will be necessary to add policies to the scale, especially policies to reduce the harmfulness of tobacco products. At the moment regulation of nicotine and tobacco products is not based on rational or public health grounds, so as better regulation develops in some countries, the tobacco control scale should reflect it, especially in view of its enormous potential impact on public health. There is already vigorous discussion in the tobacco control field of the role smokeless tobacco in Sweden (snus) has played in the decline in smoking prevalence. ${ }^{33-36}$

\section{The need for more funding on tobacco control and research}

In the EU, only the UK spent more than $€ 2$ per capita per year on tobacco control. The 2004 ASPECT report recommended that EU members immediately increase per capita spending by $€ 1-3$. The best system is illustrated by Iceland, where the law obliges the government to spend at least $0.9 \%$ of total consumer spending on tobacco, on tobacco control: per capita spending is $€ 2.27$ per annum. ${ }^{37}$ However, tobacco control spending by the tobacco industry appears to be extremely bad for tobacco control and tobacco control budgets. Tobacco control funding by the German government was only $€ 0.01$ per capita in 2004-an incredible 1 cent. Spending appears to be low because the tobacco industry provides funding, as the result of a five year $€ 11.8$ million contract between the German Ministry of Health and the industry. ${ }^{38}$ Belgium has a similar problem. The Rodin Foundation is a non-profit organisation founded in 2000, partly at the initiative of the finance minister, funded by the tobacco industry, with a budget of $€ 1850000$ per year for six years. ${ }^{39}$

Finally, we acknowledge that this scale is work in progress. We would like to examine how the scale relates to smoking prevalence, and develop better measures of implementation. However, this will require standardised survey data based on large, representative samples, and accurate estimates of cross border shopping and illegal tobacco trade in the 30 countries. At the moment different countries use different prevalence measures, making it extremely difficult to compare the impact of policies between countries. Such research will cost money, but in the EU spending on research and evaluation is extremely low generally. The 2004 EU funded ASPECT report concluded: "A strong science base for tobacco control policy and interventions is ... essential to improve societal understanding of the effects of tobacco on health and to best direct resources towards its control". ${ }^{26}$

\section{ACKNOWLEDGEMENTS}

This project received financial support from the European Commission's EU Public Health Programme 2003-2008 through the EC-ENSP grant agreement 2004323. Neither the European Network on Smoking Prevention nor the European Commission nor any person acting in their name can be held responsible for any use that may be made of the information contained in this document. We warmly thank the panel of experts and ENSP correspondents for their crucial contribution to the project and Michael Forrest (ENSP) for administrative support, including sending out the questionnaires to the ENSP correspondents. Thanks finally to David Sweanor, who commented on an earlier version of this paper, and Robert West for advice on scale validity and reliability.

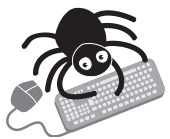

To view the questionnaire and raw data visit the Tobacco Control website-http://www. tobaccocontrol.com/supplemental

\section{Authors' affiliations}

L Joossens, Tobacco Control Manager, Belgian Foundation Against Cancer; Advocacy Officer, Association of the European Cancer Leagues, Brussels, Belgium

M Raw, Freelance consultant; honorary senior lecturer in public health science, Guy's, King's and St Thomas' Medical School, University of London, UK; visiting professor, Sao Paulo Medical School, Federal University of Sao Paulo, Brazil

Competing interests: $U$, none; $M R$, none.

\section{REFERENCES}

1 World Bank. Tobacco control at a glance, Washington DC, 2003. www.worldbank.org/tobacco.

2 Action on Smoking and Health. ASH response to Securing good health for the whole population. London: ASH, 2003.

3 Levy D, Chaloupka F, Gitchell J.' The effects of tobacco control policies on smoking rates: a tobacco control scorecard. Journal of Public Health Management and Practice 2004; 10:338-53.

4 Jha P, Chaloupka F. Curbing the epidemic. Governments and the economics of tobacco control. Washington DC: The World Bank, 1999.

5 INPES (National Health Promotion Institute). Enquête sur la prevalence du tabagisme en décembre 2003 (Survey on the prevalence of smoking in December 2003), Paris: 1 February 2004.

6 Stivoro voor een rookvrije toekomst (Foundation on Smoking or Health). Jaarverslag (Annual Report). Den Haag, 2005.

7 Fichtenberg C, Glantz S. Effect of smoke-free workplaces on smoking behaviour: systematic review. BMJ 2002;325:188-91.

8 Baver JE, Hyland A, Li Q, et al. Longitudinal assessment of the impact of smoke-free worksite policies on tobacco use. Am J Public Health 2005; 95: 1024-9

9 Office of the Revenue Commissioners. 2004 annual report, Dublin, 2005.

10 Office of Tobacco Control. Current trends in cigarette smoking. Dublin, Office of Tobacco Control, October 2005. www. otc. ie (Accessed 29 October 2005).

11 Gallus S, Zucarro P, Colombo P, et al. Effects of the new regulations in Italy. Ann Oncol advance online access (Accessed 25 November 2005).

12 Hill DJ, White VM, Scollo MM. Smoking behaviours of Australian adults in 1995: trends and concerns. Med J Austr 1998;168:209-13.

13 Farelly M, Pechacek T, Chaloupka F. The impact of tobacco control program expenditures on aggregate cigarette sales: 1981-2000. J Health Econ 2003;22:843-59.

14 Centers for Disease Control and Prevention. Best practices of comprehensive tobacco control programs. Atlanta, Georgia: CDC, 1999.

15 Saffer H, Chaloupka F. The effect of tobacco advertising bans on tobacco consumption. J Health Econ 2000;19:1117-37.

16 World Bank. Tobacco pack information at a glance. Washington DC: World Bank, June 2003, www.worldbank.org/tobacco.

17 Willemsen MC. The new EU cigarette health warnings benefit smokers who want to quit the habit: results from the Dutch Continuous Survey of Smoking Habits. Eur J Public Health 2005;15:389-92.

18 West R. Smoking: prevalence, mortality and cessation in Great Britain, 2005, www.riwest.co.uk/smokingcessation.htm, last updated 9 October 2005, last accessed 10 October, 2005.

19 World Health Organization. Policy recommendations for smoking cessation and treatment of tobacco dependence. Geneva: World Health Organization, 2003

20 SRNT/UICC website. www.treatobacco.net (Accessed 1 December 2005)

21 McNeill A, Raw M, Bauld L, et al. Smoking treatment services in England: implementation and outcomes. Addiction, 2005;100(suppl 2) www.treatobacco.net.

22 Joossens L. Effective tobacco control policies in 28 European countries, Brussels, European Network for Smoking Prevention, 2004 
23 Citigroup Smith Barney. The startling economics of tobacco. April 2005, page 34.

24 European Commission. Excise duty tables. Ref 1.020, Directorate General Taxation and Customs Union Tax Policy, January, 2005.

25 Eurostat. Statistical Office of the European Union. www.europa.eu.int/ comm/eurostat/, (Accessed 6 May 2005).

26 The ASPECT consortium. Tobacco or health in the European Union. Past present and future. Luxembourg: European Commission, 2004.

27 Wanless D. Securing good health for the whole population. Final report. London: HM Treasury, 2004.

28 Joossens L, Raw M. Turning off the tap. An update on cigarette smuggling in the UK and Sweden with recommendations to control smuggling. Brussels \& London, Cancer Research UK, London, June, 2002.

29 Joossens L, Raw M. How can cigarette smuggling be reduced? BMJ 2000;321:947-50

30 Gilpin E, Stillman F, Hartman A, Gibson J, Pierce J. Index for US state tobacco control initial outcomes. Am J Epidemiol 2000;152:727-38.

31 Chriqui JF, Frosh M, Brownson RC, et al. Application of a rating system to state clean indoor air laws (USA). Tob Control 2002;11:26-34.
32 American Lung Association. State of tobacco control 2004 report, New York, Washington DC, 2005.

33 Foulds J, Ramström L, Burke M, et al. Effect of smokeless tobacco (snus) on smoking and public health in Sweden. Tob Control 2003; 12:349-59.

34 Bates C, Fagerström K, Jarvis MJ, et al. European Union policy on smokeless tobacco: a statement in favour of evidence based regulation for public health. Tob Control 2003:12:360-7.

35 Tomar SL, Connolly GN, Wilkenfeld J, et al. Declining smoking in Sweden: is Swedish Match getting the credit for Swedish tobacco control's efforts? Tob Control 2003;12:368-71.

36 European Network on Smoking Prevention. ENSP status report on oral tobacco, Brussels, ENSP, 2003.

37 Anon. Article 15 of Act on the Prevention of the Use of Tobacco, Act No./ 2001. Reykjavik, Iceland.

38 Simpson D. Germany: still sleeping with the enemy. Tob Control 2003; 12:343-4

39 Nemery B, Joossens L, Bartsch $\mathrm{P}$, et al. Tactics of the tobacco industry in Belgium. www.bmj.com Rapid Responses for Fleck, 330 (7487) 325, 11 April, 2005.

\section{The Lighter Side}

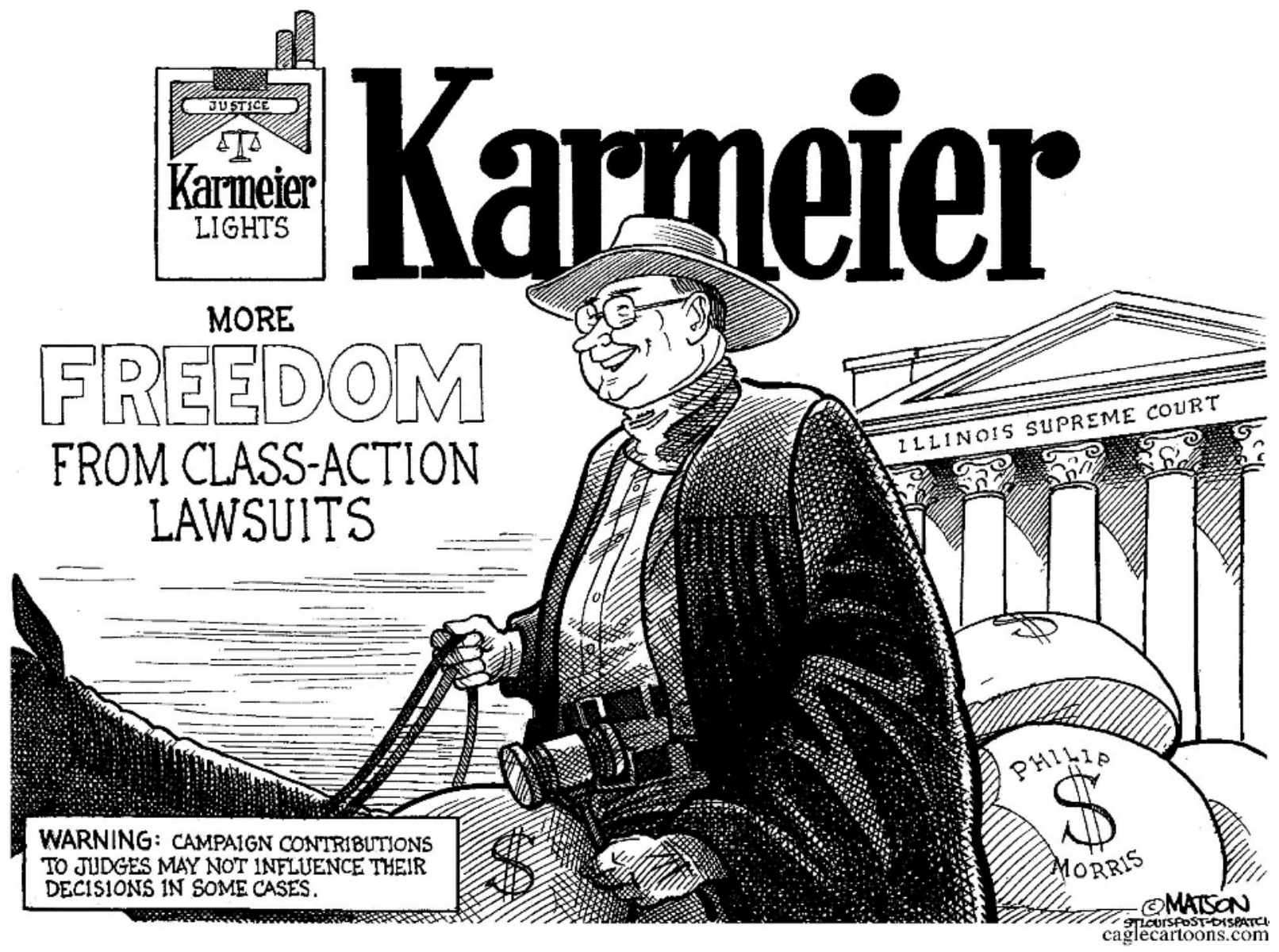

Late last year, in a 4-2 vote, the Illinois Supreme Court reversed a \$10.1 billion verdict against Philip Morris. At least one of the judges ruling in favour of the tobacco company, Justice Lloyd Karmeier, had received campaign contributions from Philip Morris.

(c) Copyright 2005 RJ Matson. All rights reserved. 